\title{
Vyacheslav Vladimirovich Meleshko
}

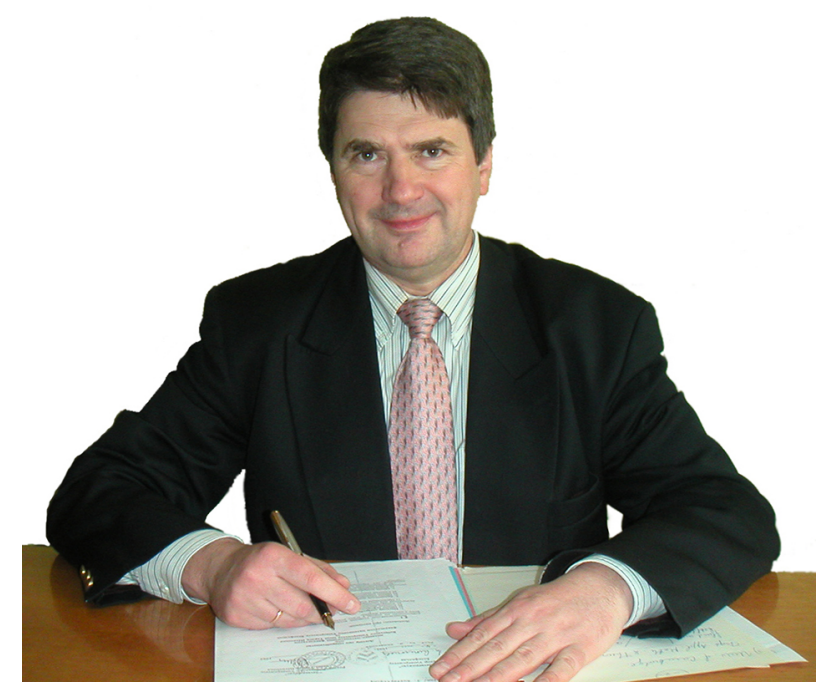

Vyacheslav (Viatcheslav) Vladimirovich Meleshko, Doctor of Physics and Mathematics, Professor and Head of the Department of Theoretical and Applied Mechanics, Faculty of Mechanics and Mathematics of Taras Shevchenko Kiev National University, passed away after a tragic accident in Kiev on 14 November 2011. He was born in a family of scientific and educational intelligentsia on 7 October 1951 in Dnepropetrovsk (now Dnipro, Ukraine). He graduated with distinction from the Faculty of Mechanics and Mathematics of Kiev National Taras Shevchenko University in 1973. In 1976 he received his Ph.D. in physics and mathematics. This was followed by postdoctoral research, which resulted in a Sc.D. thesis entitled "Laws of Steady State Wave Processes in Finite Elastic Bodies and Waveguides" and defended by him in 1984 at the Lomonosov Moscow State University. For over 6 years he worked at the Institute of Mechanics of the NAS of Ukraine, and in 1982 he obtained a position at the Institute of Hydromechanics of the NAS of Ukraine; in 1990 he became head of the new Department of Vortex Motion of that institute. From 2002 on Professor V.V. Meleshko was head of the Department of Theoretical and Applied Mechanics, Faculty Mechanics and Mathematics, Taras Shevchenko Kiev National University. Brightly and with inspiration he developed and delivered a number of lecture courses, including "Theoretical Mechanics", "Deterministic and Chaotic Oscillations", "Oscillations and Waves in Elastic Systems", "Biharmonic Problems in Mechanics", "History of Mechanics" at the Taras Shevchenko Kiev National University and the courses "Hydrodynamics of Stirring and Mixing" at Eindhoven University of Technology and Twente University (both in the Netherlands), "Advanced Dynamics" at the University of Illinois at Urbana-Champaign (USA), and "Introduction to Vortex Dynamics" at the Institute of Physics of the Atmosphere, DLR (Oberpfaffenhofen, Germany). 
V.V. Meleshko creatively combined his teaching and educational work with scientific research. He was an internationally recognized expert in fundamental areas of mechanics, as well as the theory of elasticity, hydromechanics, and acoustics. He is the author or coauthor of more than 160 scientific works, including the 3 monographs "Harmonic Oscillations and Waves in Elastic Bodies" [1], "Dynamics of Vortex Structures" [2], "Theory of Waveguides" [3]. He supervised 11 Ph.D. theses and two Sc.D. theses. He was awarded the State Prize of Ukraine in Science and Technology for the cycle of works "Regularities of Wave-vortex Processes in Continuum Media" and the Dunnuk Prize of National Academy of Sciences of Ukraine for the cycle of works "Regularities of Wave Processes in Acoustic, Elastic and Porous Elastic Finite Continuum" in 2013 (posthumously).

V. V. Meleshko's scientific collaboration with prominent foreign scientists started when it became possible to invite them to visit the USSR, and to participate in conferences abroad. Since his mother had taught him English as a child, he could communicate with foreign scientists on an informal, personal level. It was during the 3rd All-Union Workshop on Methods of Hydrophysics Research in Kaliningrad, USSR, in May 1989 that he met Dutch Professor GertJan F. van Heijst and their close and warm friendship and scientific cooperation started. As a result, Professor van Heijst invited Meleshko to be a Visiting Professor at the Fluid Dynamics Laboratory, Department of Applied Physics at Eindhoven University of Technology (TUE) in the Netherlands, and to work on several projects between 1992 and 2011. They wrote and published more than 13 articles on vortex dynamics [19, 20, 24, 28, 32, 34, 36, 37, 41, 46, 47, 52, 53]. Their collaboration was mentioned by GertJan in his warm memorial article devoted to Vyacheslav V. Meleshko [51], where he focused on a few topics that they worked on together. He mentioned a joint paper [19] on the early work of the Russian scientist Chaplygin, who had carried out detailed analytical studies of an elliptical vortex in a shear flow and of a dipolar vortex structure with a continuous vorticity distribution. The other paper that he briefly discussed is a study of vortex interactions [20]. Finally, he also highlighted some unpublished work of Meleshko and his colleagues on the behavior of vortex structures in the vicinity of solid obstacles, with or without sharp edges.

V.V. Meleshko had a considerable impact on the theory of vortex dynamics. The first works were published in 1980s [4-9]. In those articles it was shown that the nonlinear system of equations describing the mutual interaction of vortex rings has two independent invariants relating to the laws of conservation of momentum and energy. Also, relative trajectories were obtained for the special case of motion of two vortex rings of equal intensity. In 1989 Professor Meleshko started to study the chaotic motion of vortex rings [10-12]. This pioneering research led to new ideas in the study of chaotic advection problems, the concept of which was developed by the famous scientist Professor Hassan Aref in the years 1982-1984. Professor Meleshko also started to formulate and solve problems of sound emission by a system of vortex rings and sound radiation by a system of point vortices [14, 22, 27]. He studied various aspects of vortex dynamics, such as the interaction of a two-dimensional trailing vortex pair with a shear layer [33], dynamics of hairpin vortex packets in wall turbulence [38], and stability of configurations of point vortices on a sphere [48].

In 1989 V. V. Meleshko was invited by Professor Hassan Aref to take part in a IUTAM Symposium on Fluid Mechanics of Stirring and Mixing, which took place in LaJolla, USA, in August 1990. At that meeting Meleshko delivered a presentation on "Chaotic Advection of Fluid Particles in the Field of Point Vortices and Vortex Rings", and it was on that occasion that he first met Hassan. Their mutual collaboration was based on Hassan's knowledge of vortex dynamics and chaotic advection, and Meleshko's extensive knowledge of solving the 
problems of elasticity, formulated as biharmonic problems. To be precise, Meleshko realized on his flight back from the United States to Kiev in 1990 that many problems of Stokes flows and elasticity problems of bending rectangular plates require solving the (same) biharmonic equations. Besides, Meleshko was familiar with the works of famous scientists worldwide who derived solutions to elasticity or Stokes flow problems (for example, in a study of Moffatt's eddies he suggested using the works of British scientist J. N. Goodier). Professor Hassan Aref as Head of the Department of Theoretical and Applied Mechanics at the University of Illinois at UrbanaChampaign (UIUC), USA, invited Prof. Meleshko to be a Visiting Professor at the department. Together they published five papers $[26,31,39,45,53]$ and a complete Bibliography of Vortex Dynamics over the period 1858-1956, i.e., starting with the publication of von Helmholtz's celebrated landmark paper on the subject [39]. Professor Meleshko significantly contributed to new areas of basic research such as chaotic advection (the so-called Lagrangian turbulence) and chaotic mixing of liquids, microfluidics and their applications to microprocessors. He also worked on the development of basic concepts and new paradigms of chaotic advection [13, 1517, 21, 23, 25, 29, 30, 34, 35, 43] and microfluidics [42, 44]. The Vortex Dynamics section of the International Congress on Theoretical and Applied Mechanics (ICTAM-2012), which took place in Beijing (China) in August 2012, was devoted to the memory of two outstanding scientists and close friends: Professor Hassan Aref and Professor Vyacheslav (Slava) Vladimirovich Meleshko, who both passed away in 2011 .

Meleshko's works reveal a profound knowledge of the history of fluid mechanics. He rediscovered many long-forgotten works by researchers all over the world $[40,49,50]$. In particular, his close British, American, Dutch, and Italian colleagues Keith Moffatt, Hassan Aref, GertJan van Heijst, and Luca Zannetti were often amazed at how Slava Meleshko, as a scientist working in Ukraine, was able to find and dig up so many essential and important works that had been published in the past and had gone unnoticed for a long time. He combined a deep interest in scientific ideas and analytical approaches of solid and fluid mechanics problems, often going back to outstanding scientists of the past, and the possibilities of modern computers. Besides, he had a constant interest in classical experiments "with sealing wax and cord" as well as in participation in large-scale natural experiments. Professor Meleshko had an extensive knowledge of a wide variety of topics, and a dialogue with him always enriched people. Friends often called him "the walking encyclopedia". Throughout the years, he had built up a rich collection of scientific works of scientists of the past and the present, which he openly shared with colleagues and students.

He had fruitful scientific contacts with various departments of foreign universities: Eindhoven University of Technology (Netherlands), University of Illinois at Urbana-Champaign (USA), Washington University at Saint Louis (USA), Politecnico di Torino (Italy), Università di Pisa (Italy), Università di Modena (Italy), Rostov State University (Russia), the Research University of J. Nehru (National Aerospace Laboratories, Bangalore, India), National Taiwan University (Taipei, Taiwan). Within the framework of his scientific cooperation with outstanding scientists all over the world, Professor Meleshko published more than 80 articles in English in prestigious international journals like Journal of Fluid Mechanics, Physics of Fluids, Proceedings of the Royal Society of London, Quarterly Journal of Mechanics and Applied Mathematics, Fluid Dynamics Research, International Journal of Heat and Fluid Flow, Journal of the Acoustical Society of America, Journal of Elasticity, and Reviews of Modern Physics. Articles coauthored by him continued to appear even after his death $[52,53]$.

RUSSIAN JOURNAL OF NONLINEAR DYNAMICS, 2018, 14(4), 595-600 


\section{References}

[1] Grinchenko, V.T. and Meleshko, V.V., Harmonic Oscillations and Waves in Elastic Bodies, Kiev: Naukova Dumka, 1981 (Russian).

[2] Meleshko, V. V. and Konstantinov, M. Yu., Dynamics of Vortex Structures, Kiev: Naukova Dumka, 1993 (Russian).

[3] Meleshko, V. V., Matsypura, V. T., and Ulitko, I. A., Theory of Waveguides, Kiev: VPC Kiev Univ., 2003 (Ukrainian).

[4] Gurzhii, A. A., Konstantinov, M. Yu., and Meleshko, V. V., Interaction of Thin Coaxial Vortex Rings in an Ideal Fluid, Dopovidi Akad. Nauk UkrSSR. Ser. A, 1987, no. 4, pp. 40-44 (Ukrainian).

[5] Gurzhii, A.A., Konstantinov, M. Yu., and Meleshko, V. V., Interaction of Coaxial Vortex Rings in an Ideal Fluid, Fluid Dyn., 1988, vol.23, no.2, pp.224-229; see also: Izv. Akad. Nauk SSSR Mekh. Zidk. Gaza, 1988, no. 2, pp. 78-84.

[6] Meleshko, V.V. and Konstantinov, M. Yu., Collision of Two Collinear Pairs of Point Vortices in an Unbounded Ideal Fluid, Dopovidi Akad. Nauk UkrSSR. Ser. A, 1988, no.4, pp.33-37 (Ukrainian).

[7] Meleshko, V. V. and Konovalyuk, T.P., Interaction of Vortex Pair with Point Vortex in an Unbounded Ideal Fluid, Dopovidi Akad. Nauk UkrSSR. Ser. A, 1988, no. 7, pp. 41-45 (Ukrainian).

[8] Meleshko, V. V. and Konstantinov, M. Yu., Motion of Two Pairs of Point Vortices in an Ideal Fluid, Gidromekhanika, 1988, no. 58, pp. 52-55 (Russian).

[9] Meleshko, V. V. and Konstantinov, M. Yu., Motion of Vortex Ring Generated in an Ideal Fluid near Solid Walls, Fluid Mech. Soviet Res., 1991, vol.20, no.3, pp.1-6; see also: Gidromekhanika, 1989, no. 60 , pp. $56-60$.

[10] Meleshko, V. V. and Konstantinov, M. Yu., Order and Chaos in the Dynamics of the Coaxial Vortex Rings, in Proc. of the 4th Internat. Workshop on Nonlinear Physics and Turbulent Processes in Plasma (Kiev, 1989): Vol. 1, pp. 561-571.

[11] Gurzhii, A. A. and Meleshko, V. V., 2D Motion That Particles of an Ideal Fluid Execute in the Velocity Field of a Vortex Pair, Fluid Mech. Soviet Res., 1992, vol.21, no.1, pp. 106-112; see also: Gidromekhanika, 1990, no. 62, pp.60-64.

[12] Meleshko, V.V., Konstantinov, M.Yu., and Gurzhii, A.A., Ordered and Chaotic Movement in the Dynamics of Three Coaxial Vortex Rings, J. Math. Sci., 1994, vol.68, no. 5, pp. 711-714; see also: Teoret. Prikl. Mekh., 1990, no. 21, pp. 100-104.

[13] Isaeva, T. L. and Meleshko, V. V., Advection of Particles under Closed Path Motion of Cylinder in an Ideal Fluid, Dopovidi Akad. Nauk UkrSSR. Ser. A, 1991, no. 1, pp. 20-22 (Ukrainian).

[14] Meleshko, V.V. and Gurzhii, A. A., Sound Radiation by Interaction of Coaxial Vortex Rings, in Proc. of the 11th All-Union Acoustical Conf. (Moscow, 1991): Section G, pp.51-54 (Russian).

[15] Grinchenko, V.T., Isaeva, T.L., and Meleshko, V.V., Two-Dimensional Flow of Viscous Liquid in a Rectangular Cavity at Low Reynolds Number, Dopovidi Akad. Nauk UkrSSR. Ser. A, 1991, no. 8, pp. 64-70 (Ukrainian).

[16] Meleshko, V. V., Konstantinov, M. Yu., Gurzhi, A. A., and Konovaljuk, T.P., Advection of a Vortex Pair Atmosphere in a Velocity Field of Point Vortices, Phys. Fluids A, 1992, vol.4, no. 12, pp. 2779-2797.

[17] Meleshko, V. V. and Malyuga, V.S., Regular and Chaotic Advection of Fluid Particles in a Cylinder due to a Vortex Pair Velocity Field, Dopovidi Akad. Nauk Ukraine, 1993, no. 6, pp. 59-64 (Ukrainian).

[18] Meleshko, V. V., Nonstirring of an Inviscid Fluid by a Point Vortex in a Rectangle, Phys. Fluids, 1994, vol. 6, no. 1, pp. 6-8.

[19] Meleshko, V. V. and van Heijst, G. J. F., On Chaplygin's Investigations of Two-Dimensional Vortex Structures in an Inviscid Fluid, J. Fluid Mech., 1994, vol. 272, pp. 157-182. 
[20] Meleshko, V.V. and van Heijst, G. J.F., Interacting Two-Dimensional Vortex Structures: Point Vortices, Contour Kinematics and Stirring Properties, Chaos Solitons Fractals, 1994, vol. 4, no.6, pp. 977-1010.

[21] Meleshko, V.V. and Gurzhii, A. A., Stirring of an Inviscid Fluid by Interacting Point Vortices, in Modelling of Oceanic Vortices, G. J. F. van Heijst (Ed.), Amsterdam: Elsevier, 1994, pp. 271-281.

[22] Gurzhii, A. A. and Meleshko, V. V., Sound Emission by a System of Vortex Rings, Acoust. Phys., 1996, vol.42, no.1, pp.43-50; see also: Akust. Zh., 1996, vol.42, no. 1, pp. 53-61.

[23] Meleshko, V. V. and Peters, G. W. M., Periodic Points for Two-Dimensional Stokes Flow in a Rectangular Cavity, Phys. Lett. A, 1996, vol. 216, nos. 1-5, pp. 87-96.

[24] van Geffen, J.H. G. M., Meleshko, V. V., and van Heijst, G. J. F., Motion of a Two-Dimensional Monopolar Vortex in a Bounded Rectangular Domain, Phys. Fluids, 1996, vol.8, no.9, pp. 2393-2399.

[25] Meleshko, V.V., Steady Stokes Flow in a Rectangular Cavity, Proc. R. Soc. A, 1996, vol.452, no. 1952, pp. 1999-2022.

[26] Meleshko, V.V. and Aref, H., A Blinking Rotlet Model for Chaotic Advection, Phys. Fluids, 1996 , vol. 8, no. 12, pp. 3215-3217. (Erratum: "A Blinking Rotlet Model for Chaotic Advection", Phys. Fluids, 1998, vol.10, no. 6, p. 1543.)

[27] Konovalyuk, T.P. and Meleshko, V.V., Sound Radiation by the Point Vortex System, Gidromekhanika, 1996, vol. 70, pp. 41-52 (Russian).

[28] Vosbeek, P. W. C., van Geffen, J. H. G. M., Meleshko, V. V., and van Heijst, G. J. F., Collapse Interactions of Finite-Sized Two-Dimensional Vortices, Phys. Fluids, 1997, vol. 9, no. 11, pp. 3315-3322.

[29] Meleshko, V. V., Galaktionov, O.S., Peters, G. W. M., and Meijer, H. E. H., Three-Dimensional Mixing in Stokes Flow: The Partitioned Pipe Mixer Problem Revisited, Eur. J. Mech. B Fluids, 1999, vol. 18, no. 5, pp. 783-792. (Erratum: "Three-Dimensional Mixing in Stokes Flow: The Partitioned Pipe Mixer Problem Revisited", Eur. J. Mech. B Fluids, 2000, vol. 19, no. 4, p. 529.)

[30] Krasnopolskaya, T.S., Meleshko, V.V., Peters, G.W.M., and Meijer, H.E.H., Mixing in Stokes Flow in an Annular Wedge Cavity, Eur. J. Mech. B Fluids, 1999, vol.18, no. 5, pp. 793-822.

[31] Aref, H., Dunaeva, T. A., and Meleshko, V. V., Chaotic Advection by Two-Dimensional Stokes Flow in Circle, Int. J. Fluid Mech. Res., 2002, vol. 29, no. 5, pp. 525-533; see also: Prikl. Gidromekhanika, 2000, vol.2(74), no. 1, pp. 3-9.

[32] Meleshko, V.V. and van Heijst, G.J.F., Two Approaches to the Analysis of the Coaxial Interaction of Vortex Rings, Prikl. Gidromekh., 2000, vol.2(74), no.3, pp.53-59 (Russian). (See also: Grinchenko, V.T., Meleshko, V. V., Gourjii, A. A., Eisenga, A. E. M., and van Heijst, G. J. F., Two Approaches to the Analysis of the Coaxial Interaction of Vortex Rings, Int. J. Fluid Mech. Res., 2003, vol. 30, no. 2, pp. 166-183.)

[33] Meleshko, V. V., Gurzhi, A. A., Doernbrack, A., Gerz, T., Holzäpfel, F., and Hofbauer, T., Interaction of Two-Dimensional Trailing Vortex Pair with a Shear Layer, Int. Appl. Mech., 2001, vol. 37, no. 7, pp. 948-957; see also: Prikl. Mekh., 2001, vol.37, no. 7, pp. 128-136.

[34] Malyuga, V. S., Meleshko, V. V., Speetjens, M. F. M., Clercx, H. J. H., and van Heijst, G. J. F., Mixing in the Stokes Flow in a Cylindrical Container, R. Soc. Lond. Proc. Ser. A Math. Phys. Eng. Sci., 2002, vol. 458, no. 2024, pp. 1867-1885.

[35] Shankar, P. N., Meleshko, V.V., and Nikiforovich, E. I., Slow Mixed Convection in Rectangular Containers, J. Fluid Mech., 2002, vol.471, pp. 203-217.

Shankar, P.N., Meleshko, V.V., and Nikiforovich, E. I., Corrigendum: "Slow Mixed Convection in Rectangular Containers", J. Fluid Mech., 2003, vol. 495, p. 412.

[36] Gurzhii, A. A., Meleshko, V.V., and van Heijst, G. J.F., Regular and Chaotic Mixing of Fluid in a Cylinder by Vortex Pair, in Fundamental and Applied Problems of the Vortex Theory, A. V. Borisov, I. S. Mamaev, M. A. Sokolovskiy (Eds.), Izhevsk: R\&C Dynamics, Institute of Computer Science, 2003, pp. 441-467 (Russian). 
[37] Meleshko, V. V. and van Heijst, G.J.F., Mixing of Viscous Fluid in a Rectangular Cavity, Mat. Metody Fiz.-Mekh. Polya, 2006, vol. 49, no. 1, pp. 43-52 (Ukrainian).

[38] Gourjii, A. A., Meleshko, V.V., Nikiforovich, E. I., and Adrian, R. J., Dynamics of Hairpin Vortex Packets in Wall Turbulence, Prikl. Gidromekh., 2006, vol. 8, no. 2, pp. 26-49 (Russian).

[39] Meleshko, V.V. and Aref, H., A Bibliography of Vortex Dynamics 1858-1956, Adv. Appl. Mech., 2007, vol. 41, pp. 197-292.

[40] Meleshko, V.V., On Chaplygin's Investigations on Vortex Dynamics, Regul. Chaotic Dyn., 2007, vol. 12, no. 1, pp. 111-116.

[41] Meleshko, V. V. and van Heijst, G. J. F., On Chaplygin's Investigations on Coherent Vortex Structures, Regul. Chaotic Dyn., 2007, vol.12, no. 2, pp. 219-232.

[42] Meleshko, V.V., Gourjii, A.A., and Bezym'yana, E. M., Electro-Osmotic Flows of Viscous Fluid in a Rectangular Cavity, Mat. Metody Fiz.-Mekh. Polya, 2007, vol. 50, no. 1, pp. 107-116 (Ukrainian).

[43] Gourjii, A. A. and Meleshko, V. V., Process of Mixing of Passive Fluid by a Vortex Ring behind a Sphere, Prikl. Gidromekh., 2007, vol. 9, no. 1, pp. 23-35 (Russian).

[44] Berning, R., Gourjii, A. A., and Meleshko, V. V., Mixing of Viscous Fluid in a Rectangular Microchannel, Mat. Metody Fiz.-Mekh. Polya, 2007, vol. 50, no. 4, pp. 140-148 (Ukrainian).

[45] Aref, H., Meleshko, V.V., Guba, A.A., and Gourjii, A.A., Uniformly-Rotating Configurations of Point Vortices, Prikl. Gidromekh., 2007, vol. 9, nos. 3-4, pp. 3-22 (Russian).

[46] van der Woude, D., Clercx, H. J. H., van Heijst, G. J. F., and Meleshko, V. V., Stokes Flow in a Rectangular Cavity by Rotlet Forcing, Phys. Fluids, 2007, vol. 19, no. 8, 083602, 19 pp.

[47] Gourjii, A. A., Meleshko, V. V., Krasnopolskaya, T. S., Zannetti, L., van Heijst, G. J. F., and Konovalyuk, T.P., Mixing by Two-Dimensional Periodic Flows, Prikl. Gidromekh., 2008, vol. 10, no. 1, pp. 10-22 (Russian).

[48] Meleshko, V.V., Newton, P.K., and Ostrovs'kyi, V.V., Stability of the Configurations of Point Vortices on a Sphere, J. Math. Sci., 2010, vol.171, no. 5, pp.603-619; see also: Mat. Metody Fiz.Mekh. Polya, 2009, vol. 52, no. 3, pp. 146-159.

[49] Meleshko, V.V., Coaxial Vortex Rings: 150 Years after Helmholtz, Theor. Comput. Fluid Dyn., 2010, vol. 24, nos. 1-4, pp. 403-431.

[50] Meleshko, V.V., Gourjii, A.A., and Krasnopolskaya, T.S., Vortex Rings: History and State of the Art, J. Math. Sci., 2012, vol.187, no.6, pp.772-808; see also: Mat. Metody Fiz.-Mekh. Polya, 2011, vol. 54, no. 4, pp. 184-214.

[51] van Heijst, G. J.F., To the Memory of Vycheslav Vladimirovich Meleshko, J. Math. Sci., 2014, vol. 198, no. 2, pp. 217-234; see also: Mat. Metody Fiz.-Mekh. Polya, 2012, vol. 53, no. 4, pp. 171-187.

[52] Speetjens, M.F.M., Meleshko, V.V., and van Heijst, G.J.F., Spectral Analysis of Point-Vortex Dynamics: First Application to Vortex Polygons in a Circular Domain, Fluid Dynam. Res., 2014, vol. 46, no. 3, 031402, 20 pp.

[53] Aref, H., Blake, J.R., Budišić, M., Cardoso, S.S.S., Cartwright, J.H. E., Clercx, H. J. H., El Omari, K., Feudel, U., Golestanian, R., Gouillart, E., van Heijst, G. J. F., Krasnopolskaya, T. S., Le Guer, Y., MacKay, R.S., Meleshko, V.V., Metcalfe, G. Mezić, I., de Moura, A. P.S., Piro, O., Speetjens, M.F.M., Sturman, R., Thiffeault, J.-L., and Tuval, I., Frontiers of Chaotic Advection, Rev. Modern Phys., 2017, vol.89, no. 2, 025007, 66 pp. 